\title{
Enzymic Synthesis of a Diamino Sugar Nucleotide by Extracts of Type XIV Diplococcus pneumoniae ${ }^{1,2}$
}

\author{
JACK DISTLER, BERNARD KAUFMAN, AND SAUL ROSEMAN ${ }^{3}$ \\ The Rackham Arthritis Research Unit, and the Department of Biological Chemistry, The Lniversity of \\ Michigan, Ann Arbor, Michigan \\ Received June 8, 1966
}

We previously reported that incubation of the appropriate sugar nucleotides with extracts obtained from Type XIV Diplococcus pneumoniae resulted in the formation of glycolipids and serologically active polysaccharides $(1,2)$. During the course of these studies, we observed the formation of an unusual sugar nucleotide when the extracts were incubated with UDP- $N$-acetylglucosamine. As shown below, the new nucleotide is UDP-2-acetamido-4amino-2,4,6-trideoxyhexose. The extracts also transferred the diamino sugar to endogenous lipid acceptors.

While diamino sugars are found in a few antibiotics (3), the only report of the occurrence of a 2,4-diamino-2,4,6-trideoxyhexose is that by Sharon and Jeanloz (4); the unusual amino sugar was a component of a polysaccharide produced by a strain of Bacillus subtilis. The amino sugar, called bacillosamine, was obtained as the $4-N$-acetyl derivative after acid hydrolysis of the polysaccharide. Recently, Zehavi and Sharon (5) have identified bacillosamine as 2,4-diamino-2,4,6-trideoxy-L-altrose. Whether bacillosamine is identical to, or a diastereoisomer of the amino sugar reported below has not yet been established.

Two enzyme fractions were required for the synthesis of the UDP derivative of the diamino sugar. They catalyzed the following reactions:

\section{Fraction $I$}

UDP- $N$-Acetylglucosamine $\rightarrow$ UDP-2-acetamido-4-keto-2,6-dideoxyhexose (UDP-X )

\section{Fraction II}

$$
\begin{aligned}
& \text { UDP-X } \mathrm{X}_{\mathrm{I}}+\text { glutamate } \stackrel{\text { pyridoxal phosphate }}{\longleftarrow} \\
& \alpha \text {-ketoglutarate + UDP-2-acetamido-4-amino-2,4,6-trideoxyhexose (UDP-X } \mathrm{II}_{\text {II }} \text { ) }
\end{aligned}
$$

These reactions are similar to those proposed for the enzymic synthesis of TDP-4-amino4,6-dideoxyhexose from TDP-glucose (6), and perhaps for the biosynthesis of TDP-3amino-3,6-dideoxyhexose (7).

1 Dedicated to Luis F. Leloir on the occasion of his sixtieth hirthday.

2 The Rackham Arthritis Research Unit is supported by a grant from the Horace H. Rackham School of Graduate Studies of The University of Michigan. This investigation was supported by a grant from the National Arthritis and Metabolic Diseases Tnstitute of the National Institutes of Health (A-512).

${ }^{3}$ The present address of all authors is the McCollum-Pratt Institute and the Department of

\section{MATERIALS AND METHODS}

Diplococcus pneumoniae Type XIV ATCC 6314 was grown in Todd Hewitt Broth (Difco) as previously described $(1,8)$. When the culture had reached the late exponential phase of growth, it was chilled and the cells were harvested by centrifuging and washed with a solution contain-

Biology, The Johns Hopkins University, Baltimore, Maryland. 
ing $0.15 \mathrm{M} \mathrm{KCl}, \quad 0.01 \mathrm{M}$ potassium phosphate butfer, $\mathrm{pH} 7.2$.

Labeled and nonlabeled sugar nucleotides were chemically synthesized by a general method (9); UDP- $N$-acetylhexosamines- ${ }^{14} \mathrm{C}$ were labeled in the $N$-acetyl moieties.

Paper electrophoresis was performed at $60-70$ $\mathrm{V}$ per centimeter for 15-20 minutes in the following buffers: $0.05 \mathrm{~m}$ sodium eitrate, $\mathrm{pH} 4.5 ; 0.05 \mathrm{M}$ pyridinium acetate, $\mathrm{pH} 6.5$; and $0.03 \mathrm{~m}$ sodium phosphate, pH 7.5. Paper electrophoresis of labeled compounds, or of incubation mixtures containing labeled substrates, was followed by scanning the strips for radioactivity; the ${ }^{14} \mathrm{C}$ was determined by cutting the strips into half-inch segments, which were then assayed in a Packard TriCarb liquid scintillation spectrometer. The toluene scintillation system recommended by the manufacturer was used in this assay.

The following solvent systems were employed for descending chromatography on Whatman No. 1 paper at room temperature: $I$, isobutyric acidammonia-water $(57: 4: 39) ; I I, 1 \%$ ammonium sulfate-isopropanol $(1: 2) ; I I I, 0.5 \mathrm{~m}$ ammonium acctate (pH 3.8)-ethanol $(2: 5) ; I V, 1.0 \mathrm{M}$ ammonium acetate ( $\mathrm{pH} 7.5)$-ethanol $(2: 5) ; V, n$ butanol-ethanol-water $(4: 1: 1)$; and $V I$, ethyl acetate-pyridine-water $(8: 2: 1)$. The mobilities of the enzymic products, their derivatives, and reference compounds are given in Table I. Kodak blue brand X-ray film was used for the detection of ${ }^{1+} \mathrm{C}$ compounds by radioautography. After chromatography, ultraviolet light-absorbing compounds were detected by examination under an ultraviolet light, carbohydrates with a periodatebenzidine dip reagent (10), and phosphate esters with the Hanes and Isherwood spray reagent (11), followed by ultraviolet light irradiation (12).

The following colorimetric methods were used: protein by the procedure of Lowry et al. (13), hexosamines by a modified Elson-Morgan method (14), reducing sugars by the method of Park and Johnson (15), and phosphate by the method of
Fiske and SubbaRow (16). Uridine was determined by its absorbance at $262 \mathrm{~m} \mu$ in $0.075 \mathrm{M}$ phosphate buffer, $\mathrm{pH} 7$; an $E_{\max }$ of 10,000 was used.

Periodate oxidation studies were conducted in the dark at $0^{\circ}$, and periodate consumption was measured titrimetrically with a micromethod (17). Acetaldehyde was removed from the periodate reaction mixtures by bubbling a stream of moist air through the solutions; the acetaldehyde was collected in $2 \%$ sodium bisulfite and measured by the procedure of Stotz (18). A chromotropic acid method was used to determine formaldehyde in the reaction mixtures (19).

Assay of enzymes. The incubation conditions used for assaying the enzymes are given in detail in the experiments presented below, and only the principles of the assay methods are discussed here. The general procedure involved the conversion of a labeled substrate to a labeled product, separation of these by paper electrophoresis, and determination of the product by liquid scintillation techniques.

The assay of Fraction I utilized a two-step method. In the first step, Fraction I was incubated with UDP-N-acetylglucosamine- ${ }^{-14} \mathrm{C}$, giving UDP$\mathrm{X}_{\mathrm{I}^{-}}{ }^{14} \mathrm{C}$; the mixture was heated for 1 minute at $100^{\circ}$ to stop the reaction. The second step involved the conversion of UDP $-\mathrm{I}_{\mathrm{I}^{-}}{ }^{1+} \mathrm{C}$ to $\mathrm{UIDP}$ $\mathrm{X}_{\mathrm{II}^{-}}{ }^{14} \mathrm{C}$ by incubating the first reaction mixture with excess Fraction II, glutamate, and pyridoxal phosphate. Finally, the concentration of radioactive UDP-X $\mathrm{X}_{\text {II }}$ was determined after paper electrophoresis in pyridinium acetate buffer. Under the conditions described in Fig. 1, at least $96 \%$ of UDP $-\mathrm{X}_{1^{-}}{ }^{14} \mathrm{C}$ added to boiled Fraction $\mathrm{I}$ in the first step was converted to UIDP-X $\mathrm{II}^{-14} \mathrm{C}$. Control incubation mixtures, with heat-inactivated Fraction I, gave no detectable UDP-X $\mathrm{X}_{\mathrm{I}}$ ${ }^{14} \mathrm{C}$. The quantity of $\mathrm{UDDP}-\mathrm{X}_{\mathrm{I}}$ formed in the reaction was proportional to the time of incubation and to the quantity of Fraction I employed.

A unit of Fraction I was defined as the quantity

TABLE I

$R_{F}$ Values and Relative Electrophoretic Mobilities of UDP-X $\mathrm{I}_{\text {and }}$ UDP-X $\mathrm{II}$

\begin{tabular}{|c|c|c|c|c|c|c|}
\hline \multirow[b]{2}{*}{ Compound } & \multicolumn{3}{|c|}{$R_{F}$ Values in solvents } & \multicolumn{3}{|c|}{ Relative electrophoretic mobilities } \\
\hline & I & II & III & $\begin{array}{l}\text { Pyridinium } \\
\text { acetate, } \mathrm{pH} \text { o.5 }\end{array}$ & Citrate, $\mathrm{pH} 4.5$ & $\begin{array}{c}\text { Phosphate, } \\
\text { pH } 7.5\end{array}$ \\
\hline UDP- $N$-Acetylglucosamine & .37 & .33 & .08 & 1.00 & 1.00 & 1.00 \\
\hline Uridine-5'-diphosphate & .37 & .19 & .04 & & 1.29 & 1.47 \\
\hline Uridine-5'-monophosphate & .46 & .33 & .21 & .86 & .77 & 1.27 \\
\hline$U D P-X_{1}$ & .37 & & & 1.00 & 1.00 & \\
\hline UDP-X $X_{I I}$ & .46 & .14 & .07 & .49 & .44 & .74 \\
\hline$N$-Acetylglucosamine 1-phosphate & .53 & .33 & .26 & & .81 & \\
\hline
\end{tabular}


of enzyme(s) that converted $1 \mu$ mole of UDP- $N$. acetylglucosamine to product in 30 minutes at $37^{\circ}$ under the conditions described in Fig. 1.

Fraction II was assayed by measuring the reaction in the reverse direction since the quantity of UDP-X $\mathrm{X}_{\mathrm{I}}$ available for substrate was limited. Here the enzyme fraction was incubated with UDP-X $\mathrm{II}^{-14} \mathrm{C}, \quad \alpha$-ketoglutarate, and pyridoxal phosphate; after stopping the reaction, the product, UDP $-\mathrm{X}_{\mathrm{I}^{-1}}{ }^{14} \mathrm{C}$, was separated from the substrate by electrophoresis and measured by liquid scintillation techniques. Under the conditions described below, the formation of UDP-X $\mathrm{I}^{-14} \mathrm{C}$ was proportional to time of incubation and to the quantity of Fraction II.

A unit of Fraction II was defined as the quantity that converted $1 \mu$ mole of UDP-X $X_{I I}$ nto UDP $\mathrm{X}_{\mathrm{I}}$ in 30 minutes.

Preparation of Fractions $I$ and $I I$. The following operations were conducted between $0^{\circ}$ and $5^{\circ}$. The cells obtained from 6 liters of culture medium were suspended in $24 \mathrm{ml}$ of the buffer-salts solution used for washing the cells, and ruptured with a French pressure cell. After stirring for several minutes with $2 \mathrm{mg}$ crystalline DNase to reduce the viscosity, the suspension was diluted to $40 \mathrm{ml}$ and centrifuged at $32,000 g$ for 1 hour. The transluscent supernatant fluid contained the major portion of Fraction II, and was carefully separated from the particulate layer which contained both Fractions I and II. After decanting the upper layer, the tube was shaken to suspend the partially sedimented particulate fraction, and the latter was decanted. The tube was rinsed with $0.5-\mathrm{ml}$ portions of the buffer-salts mixture, followed by careful decantation; a small quantity of packed residue remaining in the tube was discarded. The crude particulate fraction contained both Fractions I and IJ, and was used to prepare UDP- $\mathrm{X}_{\mathrm{II}}$ as described below.

Fraction II could be removed from the particulate, leaving Fraction I, by storing the sediment at $0^{\circ}$ for $2-5$ days, followed by centrifuging at $32,000 \mathrm{~g}$ and washing the particles twice with fresh buffer-salts solution. The quantity of wash fluid used was equal to the volume of the original sus. pension of particles. The washed preparation was finally suspended in $4 \mathrm{ml}$ of the buffer-salts solution; it contained 5 units of Fraction I per milliliter and $8.5 \mathrm{mg}$ protein per milliliter. Fraction I was stable to storage at $-15^{\circ}$, and at $0^{\circ}$ for 1 week.

Fraction II was purified as follows. The crude supernatant fraction $(35 \mathrm{ml})$ was titrated with $1 \%$ protamine sulfate solution (about $9 \mathrm{ml}$ ) until no further precipitate was formed. After 10 minutes with occasional stirring, the mixture was centrifuged at $15,000 \mathrm{~g}$ for 10 minutes, and the precipitate was discarded. The supernatant fluid $(40 \mathrm{ml})$ was treated with $36 \mathrm{ml}$ of a saturated solution of ammonium sulfate. (The ammonium sulfate was prepared by saturating a solution at $5^{\circ}$ and adjusting with concentrated ammonium hydroxide until a $\mathrm{pH}$ of 7 was obtained when the solution was diluted 1:10 with water). After the addition of ammonium sulfate, the mixture was stirred occasionally for 20 minutes at $0^{\circ}$ and centrifuged for 10 minutes at $15,000 \mathrm{~g}$, and the residue was discarded. This residue contained all of the Fraction I activity that remained in the crude supernatant fluid, and represented about $10 \%$ of the total Fraction I activity of the crude extract; it was not soluble when resuspended in fresh buffer-salts solution, i.e., it sedimented when centrifuged at $100,000 \mathrm{~g}$. The supernatant fluid $(73 \mathrm{ml})$ obtained after the first ammonium sulfate treatment contained all of the Fraction II activity, which was in turn precipitated by adding an additional $36 \mathrm{ml}$ of the saturated ammonium sulfate solution. After occasional stirring for 15 minutes at $0^{\circ}$, followed by centrifugation for 10 minutes at $15,000 \mathrm{~g}$, the precipitate was dissolved in $4 \mathrm{ml}$ of buffer-salts solution and dialyzed for 12 hours against the same solution to remove ammonium sulfate. Finally, the dialyzed solution was centrifuged at $100,000 \mathrm{~g}$ to remove any possible contamination of Fraction II by Fraction I. A typical preparation contained 67 units of Fraction II activity, and 86 $\mathrm{mg}$ protein in a volume of $6.7 \mathrm{ml}$. The preparation was stable to storage at $-15^{\circ}$ for at least 3 weeks. Fraction II was purified approximately 10-fold over the crude extract.

\section{RESULTS}

Properties of Fraction I. Fractions I and II, obtained as described above, were crude preparations, and the results of kinetic experiments presented below are therefore considered preliminary.

The conversion of UDP- $N$-acctylglucosamine to UDP-X $\mathrm{X}_{\mathrm{I}}$ was proportional to time of incubation for at least 30 minutes, and to the quantity of Fraction I in the range 0.01-0.05 unit per incubation mixture.

The effect of $\mathrm{pH}$ on the rate of Reaction I is shown in Fig. 1. The optimum in Tris- $\mathrm{HCl}$ buffer was approximately $\mathrm{pH}$ 7.4. An apparent inhibition was observed in either phosphate or Tris-phosphate buffers.

The effect of substrate concentration on Reaction $I$ is shown in Fig. 2, and according to these results, the $K_{m}$ for UDP- $N$-acetylglucosamine was approximately $1 \times 10^{-3} \mathrm{M}$; it should be noted, however, that the particulate fraction contained UDP- $N$-acetylglucosamine $4^{\prime}$-epimerase (1), which would 


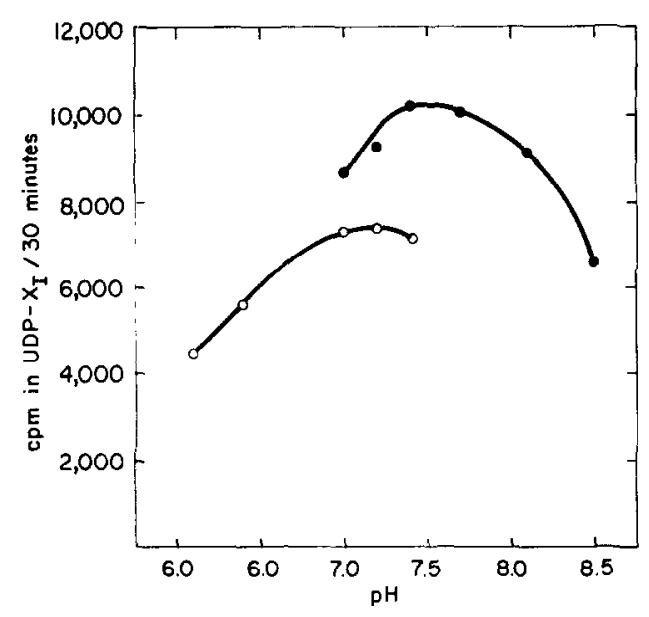

FIg. 1. The effect of $\mathrm{pH}$ on Fraction I activity. Incubation mixtures $(50 \mu \mathrm{l})$ contained $0.20 \mu \mathrm{mole}$ UI)P-N-acetylghucosamine $\left(1.8 \times 10^{5} \mathrm{cpm} / \mu\right.$ mole $)$, 0.05 unit Fraction I, and $3.3 \mu$ moles Tris- $\mathrm{HCl}$ (O) or potassium phosphate buffer (O). The mixture was incubated for 30 minutes at $37^{\circ}$ and heated to $100^{\circ}$ for 1 minute to stop the reaction. After cooling, the following additions were made: $25 \mu \mathrm{l} 0.1 \mathrm{M}$ sodium glutamate; $25 \mu \mathrm{l} 0.33$ м Tris$\mathrm{HCl}$ buffer, pH $8 ; 5 \mu \mathrm{l} 0.005$ м pyridoxal phosphate; and $25 \mu$ purified Fraction II (0.25 unit). The mixtures were incubated for 2 hours at $37^{\circ}$ and assayed by the electrophoretic method.

reduce the concentration of the substrate, and the $K_{m}$ is therefore only an estimate.

Figure 3 shows the effect of time of incubation on the reaction. The rate decreased after about 30 minutes, and the reaction essentially ceased after approximately 60 minutes. The explanation for the decrease in rate is apparently not enzyme inactivation, since the addition of fresh enzyme at 2 hours gave only a slight increase of UDP-X $\mathrm{X}_{\mathrm{I}}$. Another possibility was that the reaction had reached its equilibrium value; this explanation was not valid since only negative results were obtained in attempts to show that the reaction catalyzed by Fraction I was reversible (Table II).

One of the reasons that the rate of Reaction I abruptly decreases may be inhibition of the reaction by the product. The inhibition experiments are given in Table II; UDP-X $X_{I}$ was a powerful inhibitor of Fraction $I$, and UDP-X $X_{I I}$ also inhibited, but to a lesser extent.

Fraction I was neither stimulated nor in-

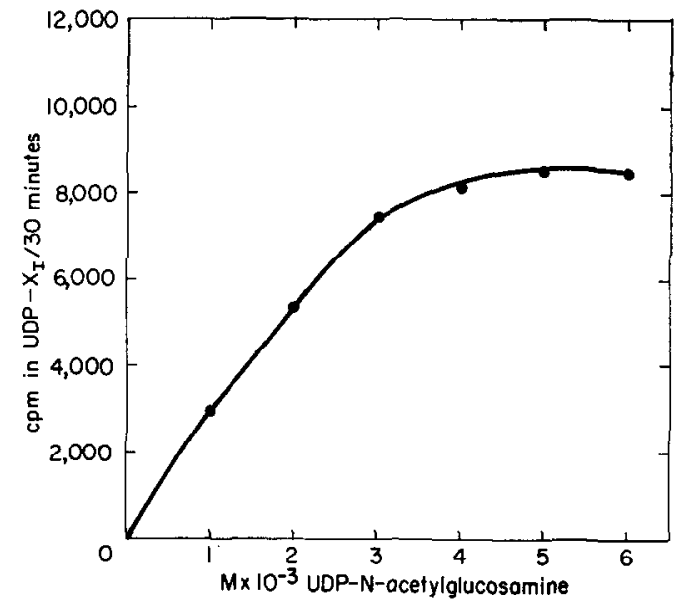

FIG. 2. The effect of substrate concentration on Reaction I. Incubation mixtures $(50 \mu \mathrm{l})$ contained: $3.3 \mu$ moles Tris- $\mathrm{HCl}$ buffer, $\mathrm{pH} 7.4 ; 0.05$ unit Fraction I; and UDP- $N$-acetylglucosamine $\left(1.8 \times 10^{5} \mathrm{cpm} / \mu\right.$ mole $)$. The reaction mixtures were treated as described in Fig. 1.

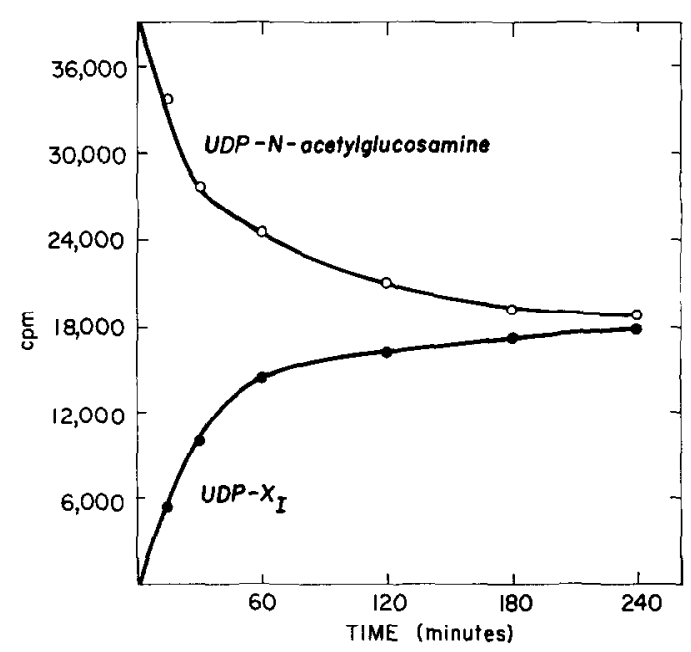

FIG. 3. Effect of time of incubation on Reaction I. Incubation conditions and assay were performed as indicated in Fig. 2. The upper curve represents the concentration of UDP- $N$-acetylglucosamine- ${ }^{14} \mathrm{C}$ in the reaction mixtures at the indicated times; the lower curve gives the concentration of UDP- $\mathrm{X}_{\mathrm{I}^{-14}} \mathrm{C}$.

hibited by concentrations of $\mathrm{MgCl}_{2}$ ranging from 0.002 to $0.01 \mathrm{M}$. However, in the presence of $0.01 \mathrm{~m}$ EDTA, the enzymic activity was inhibited to the extent of $32 \%$.

Substrate specificity studies indicated that the system was specific for UDP-N- 
TABLE II

Effect of Reaction Products on Fraction I

Incubation mixtures $\left(\begin{array}{lll}50 & \mu l\end{array}\right)$ contained: 3.3 $\mu$ moles Tris-HCl buffer, $p H$ 7.4; 0.05 unit Fraction $I$; and where indicated: UDP- $N$-acetylglucosamine $\left(1.0 \times 10^{6} \mathrm{cpm} / \mu\right.$ mole $)$, and UDP-X $X_{I}$ or UDP-X $\mathrm{II}_{\mathrm{II}}\left(4.4 \times 10^{ \pm} \mathrm{cpm} / \mu\right.$ mole $)$. The incubation mixtures were treated as described in Fig. 1 to convert UDP-X $\mathrm{X}_{1}$ to UDP-X $\mathrm{X}_{1 \mathrm{I}}$.

\begin{tabular}{|c|c|c|c|c|}
\hline \multicolumn{3}{|c|}{ Additions ( $\mu$ mole $)$} & \multirow{2}{*}{$\begin{array}{c}\text { Incubation } \\
\text { time with } \\
\text { Fraction I } \\
\quad \text { (min) }\end{array}$} & \multirow{2}{*}{$\begin{array}{l}\text { UDP-XII } \\
\text { formed by } \\
\text { Fraction II } \\
\quad \text { (cpm) }\end{array}$} \\
\hline $\mathrm{UDP}-\mathrm{X}_{\mathrm{I}}$ & UDP-XII & $\begin{array}{l}\text { UDP- } N \text {-Acetyl- } \\
\text { glucosame }\end{array}$ & & \\
\hline 0.15 & & & 0 & 6,120 \\
\hline 0.15 & & & 30 & 6,040 \\
\hline 0.15 & & & 120 & 6,310 \\
\hline 0.10 & & 0.20 & 30 & 28,700 \\
\hline \multirow[t]{5}{*}{0.10} & & 0.10 & 30 & 22,700 \\
\hline & 0.10 & 0.20 & 30 & 49,500 \\
\hline & 0.10 & 0.10 & 30 & 38,600 \\
\hline & & 0.20 & 30 & 55,100 \\
\hline & & 0.10 & 30 & 42,400 \\
\hline
\end{tabular}

acetylglucosaminc. $\Lambda$ nucleotide analogous to UDP-X $\mathrm{X}_{\text {II }}$ was not formed when the complete system was incubated with UDP. glucose, and a sugar phosphate analogous to the phosphate ester of $\mathrm{X}_{\mathrm{II}}$ was not formed when $N$-acetylglucosamine-1-P was substituted for UDP- $N$-acetylglucosamine. On the other hand, UDP- $N$-acetylgalactosamine could apparently replace UDP- $N$-acetylglucosamine. Further investigation showed, however, that this apparent activity resulted from the contaminating $4^{\prime}$-epimerase. For example, the quantity of UDP-X $X_{\text {II }}$ formed from UDP-N-acetylgalactosamine was $9 \%$ of that obtained from UDP- $N$-acetylglucosamine when the incubation was conducted for 15 minutes, and $34 \%$ after 30 minutes.

Properties of Fraction $I I$. Under the conditions described in Fig. 4, the quantity of UDP- $X_{I}$ formed from UDP- $X_{\text {II }}$ was proportional to the time of incubation for at least 30 minutes, and to the quantity of Fraction II present in the incubation mixture. As shown in the figure, the $\mathrm{pH}$ optimum in Tris$\mathrm{HCl}$ buffer was about 7.9 .

The enzymic activity was not affected by the addition of either $0.01 \mathrm{M}^{\mathrm{MgCl}}{ }_{2}$ or EDTA. On the other hand, when pyridoxal phosphate was omitted, no activity could be detected.

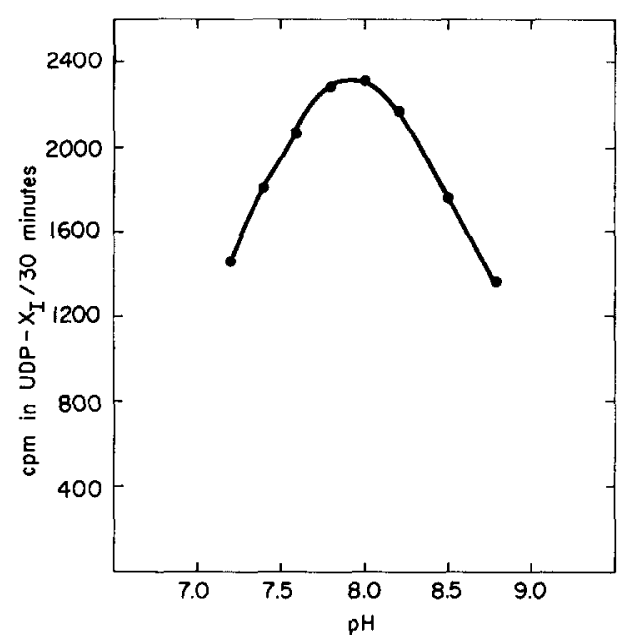

Fig. 4. The effect of $\mathrm{pH}$ on Reaction II. Inculytion mixtures $(75 \mu 1)$ contained: $0.1 \mu$ mole UDP$\mathrm{X}_{\text {II }}\left(4.4 \times 10^{4} \mathrm{cpm} / \mu\right.$ mole $) ; 2 \mu$ moles sodium $\alpha$ ketoglularale; 8 minoles Tris-HCl butfer; 0.01 $\mu$ mole pyridoxal phosphate; and 0.05 unit Fraction II. The mixture was incubated at $37^{\circ}$ for 30 minutes, the reaction was stopped by heating at $100^{\circ}$ for 1 minute, and the ${ }^{14} \mathrm{C}$-products were determined by the electrophoretie method.

The presence of $\alpha$-ketoglutarate was also essential for enzymic activity with purified Fraction II, and this compound could not be replaced by equimolar concentrations of sodium oxalacetate, pyruvate, or glyoxalate. When the complete system was used, i.e., the crude particulate preparation, glutamate was active and could not be replaced by aspartate or asparagine, and was only partially replaced by glutamine. In contrast to the reaction(s) catalyzed by Fraction I, under the proper conditions, the transaminase reaction catalyzed by Fraction II resulted in the quantitative conversion of the substrate,

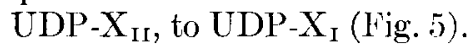

Preparation of $U D P-X_{\mathrm{II}}$. The crude particulate preparation described above, containing Fractions I and II, was used as a convenient enzyme system for the preparation of UDP-X $\mathrm{X}_{I I}$. Attempts to conduct these experiments on a large scale gave low yields of the product. The incubations were therefore conducted on a small scale, and several such mixtures were combined. A typical reaction mixture contained the following components in a final volume of $10 \mathrm{ml}: 4 \mathrm{ml}$ of the crude particulate preparation; 20 


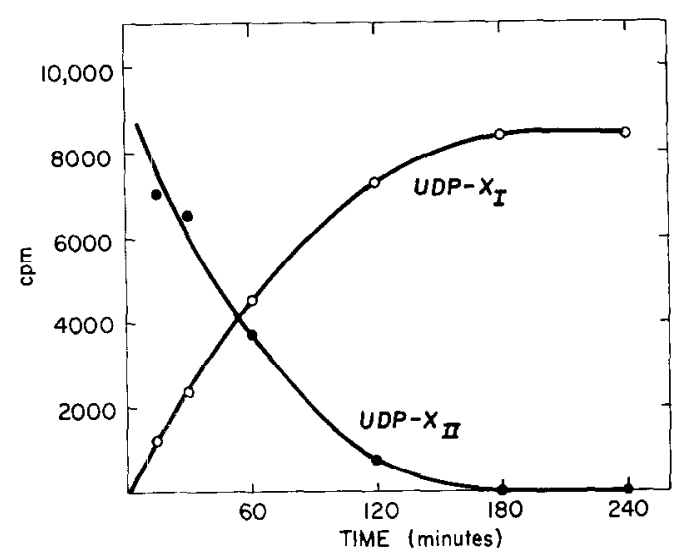

Fig. 5. The effect of time of incubation on Reaction II. Incubation mixtures were prepared as described in Fig. 4, at pH 7.9. The curves represent the quantities of $U D P-X_{I}$ and $U D P-X_{I I}$ (both ${ }^{14} \mathrm{C}$ ) present in the incubation mixtures at the indicated times.

$\mu$ moles of UDP- $N$-acetylglucosamine (labeled in the carboxyl group of the $N$-acetyl moiety, specific activity $5.5 \times 10^{4} \mathrm{cpm}$ per micromole); $100 \mu$ moles sodium glutamate; and $0.5 \mu$ mole pyridoxal phosphate. 'The $\mathrm{pH}$ of the mixture was 7.4 , and it was incubated at $37^{\circ}$ for 4 hours. Assay of aliquots showed that $57 \mu$ moles of labeled UDP-X formed during the incubation; the mixture was centrifuged at $32,000 g$ for 1 hour, and the supernatant fluid was stored at $-15^{\circ}$.

When approximately $100 \mu$ moles of UDP$\mathrm{X}_{\mathrm{II}}$ had been accumulated, the solutions were combined and filtered through a $2 \times$ $15 \mathrm{~cm}$ column of SGL charcoal. ${ }^{4}$ After washing the charcoal with water, the nucleotides were eluted with $100 \mathrm{ml}$ of a solution containing $50 \%$ ethanol and $0.6 \% \mathrm{NH}_{3}$. The eluate was concentrated to dryness in a vacuum, the residue was dissolved in $2 \mathrm{ml}$ of water, and the solution was subjected to paper electrophoresis on 30 sheets of Whatman 3 MM paper (15 inches wide each) in the

\footnotetext{
${ }^{4}$ The 6 GL charcoal, coarse mesh, was obtained from the Pittsburgh Chemical Co. It was prepared for use by repeated treatment with approximately $1 \mathrm{~N} \mathrm{HCl}$, washed with water, and then washed extensively with $50 \%$ ethanol containing $0.6 \% \mathrm{NH}_{3}$, and finally with water. The ethanolammonium hydroxide wash was important since it removed ultraviolet-absorbing and lipid-like materials from the charcoal.
}

pyridinium acetate buffer described above. The segments of the paper containing ${ }^{14} \mathrm{C}$ were eluted with water. The primary reason for the electrophoresis step was the fact that it removed inorganic phosphate, a contaminant that was difficult to remove in the subsequent stcps.

The eluate from the paper was concentrated in a vacuum and applied to a $2 \times 25$ $\mathrm{cm}$ column of Dowex-1, bicarbonate-form resin (200-400 mesh). After being washed in water, the column was eluted with a linear gradient of $\mathrm{NH}_{4} \mathrm{HCO}_{3}$; the 4-liter gradient ranged from 0.0 to $0.5 \mathrm{M} \mathrm{NH}_{4} \mathrm{HCO}_{3}$. Two radioactive peaks were detected when aliquots of the $20-\mathrm{ml}$ fractions were assayed; Peak I was observed in fractions $68-\mathbf{1 0 0}$, and Peak II was detected in fractions 106-138. Paper electrophoresis indicated that Peak I was UDP- $N$-acetylglucosamine ${ }^{-14} \mathrm{C}$, and Peak II was UDP-X ${ }_{1 I^{-14}} \mathrm{C}$; these results were surprising in view of the mobilities of these substances on paper electrophoresis. Peak II was treated in a vacuum with an excess of Dowex-50, hydrogen-form resin, to remove the $\mathrm{NH}_{4} \mathrm{HCO}_{3}$. After filtration, the solution was neutralized with $\mathrm{NH}_{4} \mathrm{OH}$, concentrated in a vacuum, and applied to a $2 \times 25 \mathrm{~cm}$ column of Dowex-1, chloride-form resin (200-400 mesh). The column was first washed with $0.003 \mathrm{M} \mathrm{HCl}$ to remove small amounts of ultraviolet light-absorbing materials, and then eluted with $1500 \mathrm{ml}$ of 0.005 a $\mathrm{LiCl}$ in $0.003 \mathrm{~N} \mathrm{HCl}$. The fractions containing UDP-X $\mathrm{X}_{\mathrm{II}}$ were combined, adjusted to $\mathrm{pH} 7$ with $\mathrm{LiOH}$, and concentrated to dryness in a vacuum. Finally, the solid was dissolved in $3 \mathrm{ml}$ of methanol, the UDP-X was precipitated by the addition of $.37 \mathrm{ml}$ of acetone, and the precipitate was collected by centrifugation, dissolved in methanol, again precipitated with acetone, and collected by centrifugation. The resulting white powder was dried over calcium chloride, in a vacuum, for 24 hours; it weighed $49 \mathrm{mg}$ and was obtained in $75 \%$ yield.

Properties of $U D P-X_{I T^{-}}{ }^{14} C$. The product obtained as described above was homogeneous when examined by paper chromatography (solvent systems I, II, III, and IV), and paper electrophoresis (3 $\mathrm{pH}$ 's). The ultraviolet light absorption spectrum of UDP-X $X_{I I}$ corresponded exactly to that of 
UMP at $\mathrm{pH} 2,7$, and 9.5. Different preparations showed only traces of inorganic phosphate, while the organic $P$ to uridine molar ratio was 1.87 . On a weight basis, the uridine content indicated that the molecular weight of the product was 754 . The specific radioactivity, $4.4 \times 10^{4} \mathrm{cpm}$ per micromole of uridine, was lower than that of the substrate, $5.5 \times 10^{4}$.

The presence of a free amino group in $\mathrm{UDP}-\mathrm{X}_{\mathrm{II}}$, in addition to the $N$-acetyl $-{ }^{14} \mathrm{C}$ group, was shown by the following: (a) The product reacted with ninhydrin on the paper chromatograms. (b) Under the standard conditions used for $N$-acetylation of hexosamines (20), the product was converted to a substance that migrated on paper electrophoresis in the same manner as UDP- $N$ acetylglucosamine. The labeled acetyl group was retained during this procedure. (c)

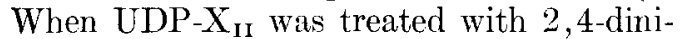
trofluorobenzene (21), a compound was formed that migrated on paper electrophoresis more rapidly than $U D P-X_{I I}$; the yellow dinitrophenyl spot corresponded to the radivaclive spol (Fig. 6).

Quantitative estimation of the reaction with 2,4-dinitrofluorobenzene showed that approximately one mole of the reagent reacted per mole of uridine, thus indicating that the UDP-X $X_{\text {II }}$ contained one free amino group. It was possible that this group was derived from the amino group of the $N$ acetylglucosamine residue by an acyl migration, thereby retaining the ${ }^{14} \mathrm{C}$ in the product, but as an acetyl ester. However, this appeared unlikely when we observed that the acetyl group was completely stable to alkali under conditions that would quantitatively hydrolyze $O$-acetyl esters.

An important property of UDP-X $X_{I I}$ was its lability to acid. For example, when treated with $0.1 \mathrm{~N} \mathrm{HCl}$ for 10 minutes at $100^{\circ}$, the colorless solution of UDP-X $X_{\text {II }}$ quickly turned red and then darkened with the formation of considerable humin. Examination of the mixture by paper electrophoresis showed UDP as the major identifiable substance, with small amounts of UMP, and a little of the original nucleotide. The hydrolysis of UDP-X $\mathrm{X}_{\text {Ir }}$ gave one mole of $\mathrm{NH}_{3}$ (Fig. 7). This decomposition, and the formation of the humin, could

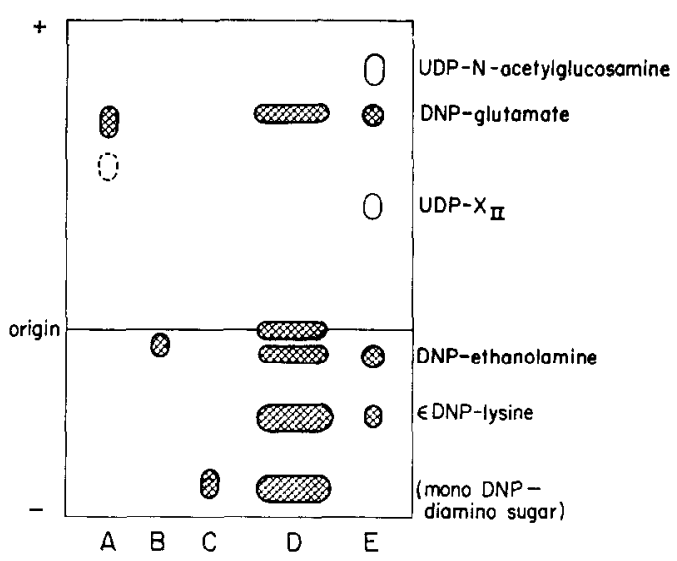

FIg. 6. Electrophoresis of DNP-derivatives of the diamino-sugars in citrate bufter, $\mathrm{pH}$ 4.5. $A$; UIPP-XII-DNP, prepared as follows: A mixture containing $50 \mu \mathrm{l} 0.01 \mathrm{M}$ UI)P-X $\mathrm{X}_{\mathrm{II}}, 50 \mu \mathrm{l} 5^{(\mathrm{c}}(\mathrm{v} / \mathrm{v})$ triethylamine, and $200 \mu \mathrm{l} 5 \%$, 2, 4-dinitrofluorobenzene in ethyl alcohol was placed in the dark for 3 hours. The solvent was removed in a vacuum, $0.25 \mathrm{ml} 5 \%$ triethylamine was added, and the solution was extracted with ether $4-5$ times. The aqueous phase was subjected to electrophoresis. $B$; the product in $A$ was hydrolyzed in $0.1 \mathrm{~N} \mathrm{HCl}$ at $100^{\circ}$ for 15 minutes, and the $\mathrm{HCl}$ was removed in a vacuum over $\mathrm{CaCl}_{2}$ and soda lime. $W_{\text {ater was }}$ added and the mixture was subjected to electrophoresis. $C$; the same as $B$ except that hydrolysis was performed in $2 \mathrm{~N} \mathrm{HCl}$ for 2 hours. $D$; the IJNP derivative of " $\mathrm{C}$ " polysaccharide was prepared as described in $A$ and hydrolyzed at $100^{\circ}$ in $2 \mathrm{~N}$ IICl for 2 hours. The hydrolysate was dried and electrophoresis was performed as above. $E$; reference compounds. Cross hatching indicates yellow oolor on the paper.

largely be prevented when the acid treatment was conducted with the derivatives formed by $N$-acetylation or by dinitrophenylation. Even here, however, vigorous acid hydrolysis resulted in decomposition.

The decomposition of UDP-X $\mathrm{X}_{\text {II }}$ under acid conditions suggested the possibility that pyrroles were being formed, and this possibility was tested with the Ehrlich reagent (24). A positive test was obtained; when the reaction was conducted at $80^{\circ}$ for 5 minutes (Table III), the absorption maximum was at $550 \mathrm{~m} \mu$, and the molar extinction coefficient (based on uridine) was $7.6 \times 10^{3}$. The optimum conditions for performing the direct Ehrlich reaction on this substance have not been established; the color was not stable to 


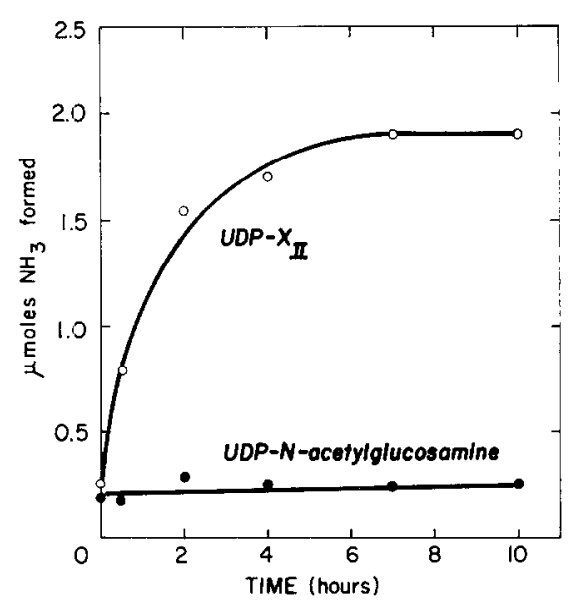

FIG. 7 . The liberation of $\mathrm{NH}_{3}$ during hydrolysis of UDP-XiT . Hydrolysis mixtures $(1.3 \mathrm{ml})$ contained $2.14 \mu$ moles of UDP-X II $_{\text {or }} 2.0 \mu$ moles UDP$N$-acetylghucosamine in $2 \mathrm{~N} \mathrm{HCl}$. The mixtures were heated at $100^{\circ}$ and aliquots were removed at various times. Ammonia was determined in the aliquots by the Conway diffusion technique (22) followed by nesslerization (23). A standard solution of $\left(\mathrm{NH}_{4}\right)_{2} \mathrm{AO}_{4}$ treated in the same manner gave quantitative yields of $\mathrm{NH}_{3}$ by this procediure.

longer periods of heating. The application of the Ehrlich reaction to the analysis of $\mathrm{X}_{\mathrm{II}}$ is discussed below. UDP-X $\mathrm{X}_{\mathrm{II}}$ also gave a positive reaction with the resorcinol reagent (25); the absorption maximum was at 590 $\mathrm{m} \mu$, and the molar extinction coefficient was $2.3 \times 10^{3}$. As with the Ehrlich reagent (discussed below), the resorcinol reagent gave no color with $\mathrm{X}_{\mathrm{II}}$ after reduction with sodium borohydride, and considerably less color with the acetyl derivative of $\mathrm{X}_{\mathrm{II}}$ (obtained by $N$-acetylation with acetic anhydride).

Isolation and properties of the phosphate ester of $X_{I I}$. Preliminary experiments showed that UDP- $X_{I I}$ was hydrolyzed by venom phosphodiesterase to UMP (identified by chromatography in solvent systems I, II, III, and IV), and to a radioactive compound that migrated very slowly on paper electrophoresis in citrate or pyridinium acetate buffers. The ${ }^{14} \mathrm{C}$ product was isolated from large-scale incubation mixtures containing the following components in final volumes of $5 \mathrm{ml}: 75 \mu$ moles UDP-X $\mathrm{II}^{-14} \mathrm{C}$; $50 \mu$ moles $\mathrm{MgCl}_{2} ; 175 \mu$ moles Tris- $\mathrm{HCl}$ buffer, $\mathrm{pH} 7.8$; and 600 units of venom phosphodiesterase
(California Biochemical Corp.). After 1 hour at $37^{\circ}$, electrophoresis of an aliquot showed that $80 \%$ of the substrate had been converted to a product that remained close to the origin. The product was isolated by a procedure used for the purification of other hexosamine phosphates (26); the reaction mixture was applied to a column containing $500 \mathrm{ml}$ of Dowex-50, hydrogen-form resin (200-400 mesh), and eluted with water. A small fraction of the total radioactivity was eluted with the salts in the first $400 \mathrm{ml}$, and the bulk of the radioactivity was eluted in a peak emerging between 4350 and $4850 \mathrm{ml}$ of cluant. The latter was evaporated to dryness in a vacuum, dissolved in $0.5 \mathrm{ml}$ of water, and treated with $1.5 \mathrm{ml}$ of ethanol and 1.5 $\mathrm{ml}$ of acetone. After storage at $5^{\circ}$, the product crystallized as fine needles which were collected by centrifugation, washed with an ethanol-acetone mixture $(1: 1)$, and dried over calcium chloride in a vacuum. The product weighed $10 \mathrm{mg}$ and was recrystallized from a water-ethanol-acetone mixture. After drying over $\mathrm{P}_{2} \mathrm{O}_{5}$ in a vacuum for 24 hours, it exhibited $[\alpha]_{\mathrm{D}}^{25}=+126^{\circ}(c, 0.3$ in water), and gave the following elemental analyses (Spang Microanalytical Laboratory, Ann Arbor, Michigan).

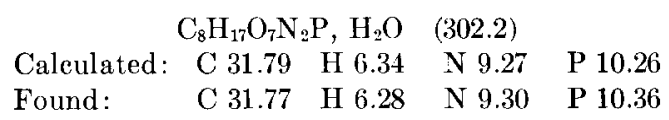

The crystalline product did not give a reducing sugar test but reacted with ninhydrin on paper chromatograms.

Preparation and Reduction of $X_{I I}$ and of $\mathrm{N}$-acetyl- $X_{I I} \cdot \mathrm{X}_{\mathrm{II}}$, its $N$-acetyl derivative, and the corresponding sugar alcohols were prepared from $\mathrm{X}_{\mathrm{II}^{-}}-1-\mathrm{P}$. Since the latter compound could not be hydrolyzed with acid without concomitant destruction, the phosphate group was removed by enzymic hydrolysis. Treatment of $\mathrm{X}_{\mathrm{II}}-1-\mathrm{P}(6 \mu$ moles adjusted to $\mathrm{pH} 8$ with $\mathrm{NaOH}$ ) with 0.1 mg Escherichia coli alkaline phosphatase (Worthington Biochemical Corp.) for 1-3 hours at $37^{\circ}$ gave a product that showed a positive charge on paper electrophoresis in citrate buffer. The reaction was conducted until the phosphate ester was completely hydrolyzed. At this point, aliquots were directly $N$-acetylated with acetic anhydride 
TABLE III

Colorimetric Analysis of the Diamino Sugars

\begin{tabular}{|c|c|c|c|}
\hline Compound & Amount analyzed ( $\mu$ moles) & $\begin{array}{c}\text { Direct Ehrilich' }{ }^{a}{ }^{a} \\
\text { (absorbance) }\end{array}$ & $\underset{\text { (absorbance) }}{\text { Dinitrophenylation }}$ \\
\hline \multirow{4}{*}{$U D P-X_{I I}$} & 0.022 & 0.149 & 0.069 \\
\hline & 0.044 & 0.275 & 0.149 \\
\hline & 0.11 & 0.625 & 0.361 \\
\hline & 0.22 & 1.380 & 0.705 \\
\hline $\mathrm{UDP}-\mathrm{X}_{\mathrm{II}}$ & 0.10 & 0.66 & \\
\hline $\mathrm{X}_{\text {II }}$ (free sugar) & 0.10 & 1.81 & \\
\hline$N$-Acetyl-X $\mathrm{X}_{\text {II }}$ (free sugar) & 0.10 & 1.24 & 0.00 \\
\hline UDP-N-Acetyl-XII & 0.10 & 0.361 & 0.00 \\
\hline $\mathrm{NaBH}_{4}$ reduced $\mathrm{X}_{\mathrm{II}}$ & 0.10 & 0.00 & \\
\hline $\mathrm{NaBH}_{4}$ reduced $N$-acetyl-X II & 0.10 & 0.00 & \\
\hline \multirow[t]{3}{*}{ "C" polysaccharide ${ }^{c}$} & $0.50 \mathrm{mg}$ & 0.205 & \\
\hline & $0.25 \mathrm{mg}$ & 0.102 & 0.133 \\
\hline & $0.125 \mathrm{mg}$ & & 0.062 \\
\hline SXIV polysaceharided & $0.50 \mathrm{mg}$ & 0.00 & 0.00 \\
\hline
\end{tabular}

a An aqueous solution $(0.1 \mathrm{ml})$ containing the substance to be analyzed, $0.9 \mathrm{ml}$ ethyl alcohol, and $0.2 \mathrm{ml}$ Ehrlich's reagent $(0.5 \%$-dimethylaminobenzaldehyde in 1:1 concentrated HCl-ethyl alcohol) was heated at $80^{\circ}$ for 5 minutes and cooled in tap water. The absorbance of the solution was determined at $550 \mathrm{~m} \mu$ after 30 minutes.

$b$ The DNP derivative of the substance to be analyzed was prepared as described in Fig. 6C. After preparation of the derivative, the samples were hydrolyzed in $2 \mathrm{~N} \mathrm{HCl}$ at $100^{\circ}$ for 2 hours. The solution was evaporated over $\mathrm{CaCl}_{2}$ and soda lime, $0.1 \mathrm{ml}$ water was added, and $0.05 \mathrm{ml}$ was subjected to electrophoresis (citrate buffer). After drying the paper, the yellow spots corresponding to DNP-diamino sugar were suspended in $2 \mathrm{ml} 0.01 \mathrm{~N} \mathrm{HCl}$ for 4 hours, and the absorbancies of the solution were determined at $360 \mathrm{~m} \mu$.

${ }^{c}$ Generously supplied by Dr. Emil Gotschlich (Rockefeller Institute).

${ }^{d}$ Kindly provided by Dr. Michael Heidelberger (New York University).

(20), or were reduced with sodium borohydride, or were first $N$-acetylated and then reduced. These procedures gave reduced $X_{\text {II }}$ and reduced $N$-acetyl-X $\mathrm{X}_{\text {II }}$. The borohydride reductions were performed by adding a 100 fold excess of $\mathrm{NaHB}_{4}$ to the reaction mixtures over a period of 30 minutes. The excess borohydride was destroyed by adding $\mathrm{HCl}$ to $\mathrm{pH} 4$, and the mixtures were passed through a column of Dowex-1, chloride-form resin, to remove borate ion. The eluates were concentrated in a vacuum to $0.5 \mathrm{ml}$ and treated with 5 volumes of ethanol to precipitate the bulk of the $\mathrm{NaCl}$. After filtration, the salt was washed with ethanol, the filtrates were concentrated, and the products were purified by chromatography on Whatman No. 1 paper in solvent system V; the labeled products were detected by radioautography. The sugar alcobol derived from $\mathrm{X}_{\text {II }}$ migrated with an $R_{F}=0.29$, while the
$R_{F}$ of the $N$-acetyl derivative was 0.50 . The products were eluted from the paper with water and oxidized with sodium periodate. As shown in Table IV, the alcohol corresponding to $\mathrm{X}_{1 \mathrm{I}}$ consumed 2 moles of periodate, gave 0.86 mole of acetaldehyde, and no detectable formaldehyde. By contrast, the alcohol corresponding to $N$-acetyl-X $\mathrm{X}_{\text {II }}$ consumed less than 0.2 mole of periodate and gave no detectable acetaldehyde or formaldehyde. The eluate of a control segment of the chromatography paper per se did not consume significant quantities of periodale. The sugar alcohols obtained from $\mathrm{X}_{\mathrm{II}}$ and $N$-acetyl-X $\mathrm{X}_{\mathrm{II}}$ were radioactive and therefore contained the labeled $N$-acetyl group originally present in the UDP-Nacetylglucosamine $-{ }^{14} \mathrm{C}$. Since this acetamido group was located at C-2 of the hexosamine, the results of the periodate oxidation studies with the sugar alcohols are only consistent 
TABLE IV

Periodate Studies with the Diamino Sugars ${ }^{a}$

\begin{tabular}{ccc}
\hline Oxidation time & $\begin{array}{c}\mathrm{NaBH}_{4} \text { reduced } \mathrm{X}_{\mathrm{II}} \\
\text { (moles IO } \\
\text { sugar) }\end{array}$ & $\begin{array}{c}\mathrm{NaBH}_{4} \text { reduced } N- \\
\text { acetyl-X } \\
\text { IO } \text { I }_{1} / \text { mole sugar) }\end{array}$ \\
\hline 15 minutes & 1.37 & 0.12 \\
30 minutes & 1.58 & 0.14 \\
2 hours & 2.10 & 0.14 \\
4 hours & 2.01 & 0.20 \\
8 hours & 2.06 & 0.17 \\
\hline
\end{tabular}

a The reaction mixtures contained the following components in $1 \mathrm{ml}: 1.90 \mu$ moles reduced $\mathrm{X}_{\mathrm{II}}$ or $2 \mu$ moles reduced $N$-acetyl-X ${ }_{\text {II }}$, determined by ${ }^{14} \mathrm{C}$-content; $20 \mu$ moles sodium periodate; and 200 $\mu$ moles acetate buffer, $\rho H$ 4.5. The reaction mixtures were maintained at $0^{\circ}$ in the dark, and aliquots were removed for analysis. The values represent periodate consumption per mole of sugar, and these were determined by a microtitrimetric method utilizing arsenite (17). Other reaction mixtures were analyzed for aldehydes as described in Methods. Acetaldehyde was obtained on periodate treatment of reduced $\mathrm{X}_{\mathrm{II}}$ (0.86 mole per mole ${ }^{14} \mathrm{C}$-sugar) but not from reduced $N$-acetyl- $\mathbf{X}_{\text {II }}$. Formaldehyde was not obtained as a product of periodate oxidation of either sugar.

with a 6-deoxy group at C-6 (which gave acetaldehyde), and with an amino function at C-4. The periodate oxidation studies, along with the other properties of UDP-X-II and the crystalline $X_{I I}$-phosphate described above, showed that $X_{\text {II }}$ was a 2 -acetamido-4amino-2, 4,6-lrideoxyhexose. The configuration of the sugar has not yet been established, and its possible relationship to bacillosamine has been discussed above.

Preparation of $U D P-X_{I}$. The most convenient method for the preparation of this nucleotide was from UDP- $X_{I I}$, using Fraction II. When the incubation was conducted on a large scale $\left(10 \mu\right.$ moles of UDP-X $\left.X_{I I}\right)$ as described in Fig. 5, for 2 hours, essentially all of the UDP-X $\mathrm{X}_{\mathrm{II}}$ was converted to UDP-X . $_{\text {. }}$ The latter was isolated after electrophoresis of the mixture in pyridinium acetate buffer, and the eluate from the paper was applied to a $1 \times 10 \mathrm{~cm}$ Dowex-1, chloride-form column (200-400 mesh). After washing the column with water, it was eluted with $0.003 \mathrm{~N} \mathrm{HCl}$ in a linear gradient of $\mathrm{LiCl}$, ranging from 0.0 to $0.08 \mathrm{M}$, in a total volume of 1 liter. The fractions, $10 \mathrm{ml}$ each, were assayed for nucleotide and for ${ }^{14} \mathrm{C}$; only one peak was detected, in fractions 61-80. The appropriate fractions were combined, the solution was filtered through a 5 -ml column containing SGL coarse mesh charcoal, ${ }^{4}$ the charcoal was washed with water, and the nucleotide was cluted with ethanol-water-ammonia as described above. The product was finally obtained by concentrating the eluate to dryness in a vacuum.

The product, UDP-X $\mathrm{X}_{\mathrm{I}}$, was a substrate for Fraction II, being converted in $96 \%$ yield to UDP-X $\mathrm{X}_{\text {Ix }}$ upon incubation with the transaminase, in the presence of pyridoxal phosphate and excess glutamate. The ultraviolet absorption spectrum of the nucleotide at $\mathrm{pH}$ 7 was characteristic of UMP, but also showed "end absorption" in the range below $230 \mathrm{~m} \mu$. The end-absorbing substance(s) was not removed by an additional purification by paper electrophoresis. Furthermore, the ratio of ultraviolet light absorbancy to ${ }^{14} \mathrm{C}$ was about $12 \%$ higher than that of the substrate, UDP-X $X_{I I}$. These results suggest an impurity that was not removed by the purification procedures, or that the carbonyl group may contribute significantly to the absorption spectrum.

The nucleotide contained a carbonyl function as indicated by the following: (a) It reacted with o-phenylenediamine (27), and the reaction product showed the expected light absorption spectrum with a molar extinction coefficient at $335 \mathrm{~m} \mu$ of $5.2 \times 10^{3}$. (b) The nucleotide gave a positive reducing sugar test (15) without prior acid hydrolysis. (c) After hydrolysis with acid, a negative hexosamine reaction was obtained with the Flson-Morgan reagents. However, if the nucleotide was first reduced with sodium borohydride, and then subjected to this procedure, the Elson-MIorgan test was positive.

The hexosamine(s) from UDP-X $\mathrm{X}_{\mathrm{I}}$ was prepared as follows. UDP-X $\mathrm{I}_{\mathrm{I}}(2 \mu$ moles $)$ was reduced with sodium borohydride, adsorbed on charcoal, eluted, and hydrolyzed in $4 \mathrm{~N}$ $\mathrm{HCl}$ at $100^{\circ}$ for 4 hours. The hydrolyzate was dried over soda lime and calcium chloride to remove the $\mathrm{HCl}$, and the residue was chromatographed by the procedure of Gardell (28). The results shown in Fig. 8 clearly showed that the products obtained from UDP-X $X_{I}$ were neither glucosamine nor 


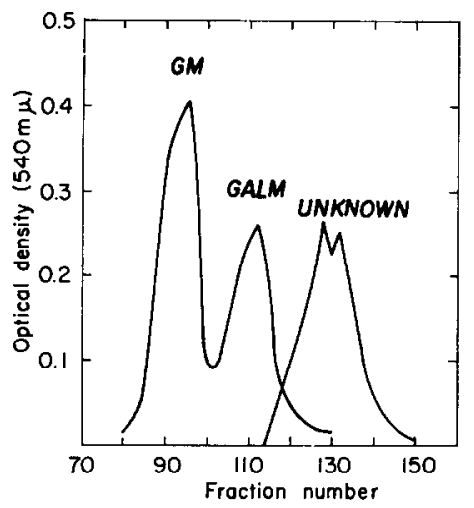

Fig. 8. Chromatography of the hexosamines from reduced UDP- $X_{I}$ on 1)owex-50 $\left(\mathrm{H}^{+}\right)$. The hexosamines obtained from $1 \mu$ mole UDP-X $X_{I}$ were chromatographed by the procedure of Gardell (28). The column was $1 \times 46 \mathrm{~cm}, 200-400$ mesh, Dowex-50 $\left(\mathrm{H}^{+}\right)$; the eluant was $0.3 \mathrm{~N} \mathrm{HCl}$, and $1.78-\mathrm{ml}$ fractions were collected. Glucosamine and galactosamine standards were chromatographed in the same manner. Alternate fractions were analyzed for hexosamine after drying over $\mathrm{CaCl}_{2}$ and soda lime.

galactosamine. The hexosamine fractions were combined, concentrated, and degraded with ninhydrin by the procedure of Stoffyn and Jeanloz (29). The degraded sugar(s) migrated more rapidly than standard pentoses: in solvent system $V$, the $R_{\text {ribose }}$ was 1.81, while in solvent system VI, the $R_{\text {ribose }}$ was 2.51. These results agreed with those obtained by ion-exchange chromatography of the hexosamine(s), and would be expected if the hexosamines derived from $X_{I}$ were the 2-amino-2,6-dideoxyhexoses.

The characterization of $U \mathrm{DP}-\mathrm{X}_{\mathrm{I}}$ has not been completed. Nevertheless, all of the evidence presented above, i.e., its origin from UDP-X $X_{I 1}$ by a reaction that shows all of the properties of a transamination, the fact that it contains a carbonyl group, that it gives hexosamines on reduction which are not glucosamine or galactosamine, and that these hexosamines are not degraded by ninhydrin to known pentoses but to substances that appear to be less polar, suggest that $X_{I}$ is a 4-keto-2-acetamido-2,6-dideoxyhexose. The origin of this compound from UDP- $N$-acetylglucosamine would be analogous to the reactions involving the conversion of several hexose nucleotides to the corresponding 4keto-6-deoxyhexose nucleotides (30), the latter being intermediates in the formation of substances such as GDP-L-fucose.

Detection of $X_{1 I}$ in biological materials. As emphasized above, the diamino sugar, $X_{I T}$, rapidly decomposes in acid. It therefore appears possible that this or similar substances may occur in biological substances, but have hitherto escaped detection with the exception of bacillosamine (4). The direct Ehrlich reaction, which probably depends upon the conversion of $\mathrm{X}_{\mathrm{II}}$ to pyrroles (ring closure would involve the $\mathrm{C}-4$ amino and $\mathrm{C}-1$ aldehyde groups), can be used to detect $\mathrm{X}_{\mathrm{II}}$, but this reaction would be dependent on $X_{I I}$ glycosides being sensitive to hydrolysis so that cleavage could occur under the relatively mild acid conditions used in the Ehrlich test. In fact, the free amino sugar, $\mathrm{X}_{\mathrm{II}}$, obtained by the enzymic hydrolytic methods described above, reacted with the Ehrlich reagent at room temperature and gave about 2.8 times as much color, under the conditions shown in Table III, as an equimolar quantity of UDP-X $\mathrm{X}_{\mathrm{II}}$. In addition, the amino group at $\mathrm{C}-4$ of $\mathrm{X}_{\mathrm{II}}$ may be acylated in natural substances, and this would either decrease the reactivity with the Ehrlich reagent (e.g., see Table III for the reaction shown by the $N$-acetyl derivative), or might result in a negative test. Thus, a negative Fhrlich test would not be evidence for the absence of this sugar.

An alternate method for detecting $X_{11}$ was therefore developed. In this procedure, the substance was dinitrophenylated and hydrolyzed with acid, and the hydrolyzate was subjected to electrophoresis. 'The DNP$\mathrm{X}_{\mathrm{II}}$ migrated more rapidly than did amino acid derivatives (Fig. 6); the positive charge resulted from liberation of the amino group at $\mathrm{C}-2$, i.e., cleavage of the acetamido group by the acid treatment. This method suffers, of course, from the limitation that the amino group of $X_{I I}$ must be available for dinitrophenylation.

The colorimetric and dinitrophenylation methods were applied to the analysis of "C" polysaccharide (31) and to the Type XIV specific capsular polysaccharide. As shown in Table III, Type XIV polysaccharide gave negative results, but the highly purified " $\mathrm{C}$ " polysaccharide gave positive results by both methods, and the results suggest that this 
substance contains a substantial quantity of $\mathrm{X}_{\mathrm{II}}$ or similar substances, and that the amino group of the sugar is free to react with the fluorodinitrobenzene reagent.

Table III also shows that the aldehyde function of $\mathrm{X}_{\mathrm{II}}$ was required for a positive Ehrlich's test (the sugar alcohols did not react), and that $N$-acetylation of the amino group at C-4 markedly reduced the reactivity with this reagent.

Glycolipids containing $X_{I I}$. In our first studies on the biosynthesis of Type XIV polysaccharides (1), we noted the incorporation of considerable quantities of hexose into glycolipid from UDP-hexosc, and the formation of small quantities of radioactive glycolipid from labeled UDP- $N$-acetylglucosamine. The hexose containing glycolipids have been characterized as glucosyl-diglyceride, and galactosyl-glucosyl-diglyceride (2).

In the present studies, the hexosaminecontaining glycolipids were examined, and the labeled material was found to be $\mathrm{X}_{\mathrm{II}}$ and not glucosamine or galactosamine. With the crude preparations presently available, the lipid acceptor is endogenous material in the enzyme fraction, and UDP- $N$-acetylglucosamine (or UDP- $N$-acetylgalactosamine) is converted to UDP-X $\mathrm{X}_{1 \mathrm{I}}$ prior to incorporation into the lipid. Preliminary experiments showed that UDP-X $X_{I I}$ was at least as efficient a glycose donor as UDP- $N$-acetylglucosamine.

Two chromatographically pure ${ }^{14} \mathrm{C}$-lipids were isolated from the incubation mixtures; the reaction mixtures were those used for the preparation of UDP-X $X_{I I}$ described above. The lipids were purified by silicic acid column chromatography followed by thinlayer chromatography. While the complete structures of these lipids are not yet known, the following information has been obtained. (a) The lipids gave negative tests with the anthrone and Elson-Morgan (after acid hydrolysis) reagents, and therefore do not contain detectable quantities of hexose or hexosamine. (b) One of the lipids contained phosphorus, whereas the other did not. (c) Dinitrophenylation, followed by acid hydrolysis and paper electrophoresis, gave a product from each lipid that corresponded to the DNP-derivative of deacetylated $\mathrm{X}_{\text {II }}$ (see Fig. 6 C). (d) Neither the lipids nor their saponification products gave a direct Ehrlich reaction, or a reducing sugar test. (e) Upon saponification under relatively mild conditions (2), both lipids gave water-soluble fragments containing all of the ${ }^{14} \mathrm{C}$, and which were purified by chromatography on Dowex-50, hydrogen-form resin. Each of the lipids gave but one ${ }^{14} \mathrm{C}$-product, and the products from the two lipids were either the same substance or were closely related. Chemical studies with the ${ }^{14} \mathrm{C}$-water-soluble materials showed that they contained a free amino group (ninhydrin reaction, electrophoretic mobility, reaction with fluorodinitrobenzenc to yield the DNP derivative described above). $N$-Acetylation of each of the ${ }^{14} \mathrm{C}$-saponification products gave an electrophoretically neutral substance. Finally, acid hydrolysis of the saponification products gave glycerol.

The results thus far suggest that the lipids may be diglycerides where $X_{I I}$ is glycosidically bound to the glycerol moiety. The phosphorous containing lipid is, of course, more complex; perhaps it is a phosphatidyl glycerol type of molecule that contains $X_{\mathrm{II}}$.

\section{ACKNOWLEDGMENT}

We are most grateful to Mr. Benjamin Snyder for his expert assistance in some aspects of these studies.

\section{REFERENCES}

1. Distler, J., and Roseman, S., Proc. Natl. Acad. Sci. U.S. 51, 897 (1964).

2. Kaufman, B., Kundig, F., Distler, J., and Roseman, S., Biochem. Biophys. Research Commun. 18, 312 (1965).

3. Sharon, N., in "The Amino Sugars" (E. A. Balazs and R. W. Jeanloz, eds.), Vol. IIA, p. 1. Academic Press, New York (1965).

4. Sharon, N., and Jeanloz, R. W., J. Biol. Chem. 235, 1 (1960).

5. Zehavi, U., AND Sharon, N., Israel $J$. Chem. 2, 322 (1964).

6. Matsuhashi, M., ani Strominger, J. L., $J$. Biol. Chem. 239, 2454 (1964).

7. Volk, W. A., ANd Ashwelt, G., Biochem. Biophys. Res. Commun. 12, 116 (1963).

8. Distler, J., and KaUfman, B., in "Methods in Enzymology" (S. P. Colowick and N. O. Kaplan, eds.), Vol. VIII. Academic Press, New York (1966).

9. Roseman, S., Distler, J. J., Moffatt, J. G., 
and Khorana, H. G., $J, A m$. Chem. Soc. 83, 659 (1961).

10. Gordon, H. T., Thornburg, W., And Werum, L. N., Anal. Chem. 28, 849 (1956).

11. Hanes, C. S., and Isherwood, H. A., Nature 164, 1107 (1949).

12. Bandurski, R. S., and Axelrod, B., J. Biol. Chem. 193, 405 (1951).

13. Lowry, O. H., Rosebrough, N. J., Farr, A. L., ANo Randall, R. J., J. Biol. Chem. 193, 265 (1951).

14. Boas, N. F., J. Biol. Chem. 204, 553 (1953).

15. Park, J. T., ANd Johnson, M. J., J. Biol. Chem. 181, 149 (1949).

16. Fiske, C. H., and SubbaRow, Y., J. Biol. Chem. 66, 375 (1925).

17. Schiffman, G., Kabat, E. A., and Leskowitz, S., J. Am. Chem. Soc. 84, 73 (1962).

18. Sтотz, E., J. Biol. Chem. 148, 585 (1943).

19. Burton, R. M., in "Methods in Enzymology" (S. P. Colowick and N. O. Kaplan, eds.), Vol. III, p. 246. Academic Press, New York (1957).

20. Roseman, S., and Daffner, I., Anal. Chem. 28, 1743 (1956).
21. Levr, A. L., in "Methods of Biochemical Analysis" (1). (ilick, ed.), Vol. II, p. 360. Wiley (Interscience), New York (1955).

22. Conwar, E. J., "Mierodiffusion Analysis and Volumetric Error," 2nd edition, p. 92. Crosby Lockwood, London (1947).

23. Ballentine, R., in "Methods in Enzymology" (S. P. Colowick and N. O. Kaplan, eds.), Vol. III, p. 984. Academic Press, New York (1957).

24. Frомm, F., Mikrochemie 17, 141 (1935).

25. Svennerholm, I., Biochim. Biophys. Acta 24, 604 (1957).

26. Pogeld, B. M., And Gryder, R. M., J. Biol. Chem. 228, 701 (1957).

27. Ginsbura, V., J. Biol. Chem. 236, 2389 (1961).

28. Gardell, S., Acta Chem. Scand. 7, 207 (1953).

29. Stroffyn, P. J., And Jeanloz, R. W., Arch. Biochem. Biophys. 52, 373 (1954).

30. GinsburG, V., in "Advances in Enzymology" (F. F. Nord, ed.), Vol. 26, p. 35. Wiley (Interscience), New York (1964).

31. Lit, T., and Gotschlich, E. C., J. Biol. Chem. 238, 1928 (1963). 